\title{
Randomized controlled trial of the impact on the outcome of pneumonia in children receiving Vitamin D supplementation
}

\author{
Jingi J.K. ${ }^{1}$, Patil S S. ${ }^{2}$, Desai A.S. ${ }^{3}$ \\ ${ }^{1}$ Dr. Jagadish K Jingi, Junior Resident, ${ }^{2}$ Dr. Shailesh S Patil, Associate Professor, ${ }^{3}$ Dr. Arunkumar S. Desai, Professor \\ and Head, all authors are affiliated with Department of Pediatrics, Belgaum Institute of Medical Sciences, Belagavi, \\ Karnataka, India.
}

Corresponding Author: Dr Shailesh S Patil, Associate Professor, Department of Pediatrics, Belgaum Institute of Medical Sciences, Belagavi, Karnataka. Email: shaileshpt@yahoo.com

\begin{abstract}
Objective: To study whether vitamin D supplementation in children presenting with pneumonia and severe pneumonia reduce its duration of recovery. Study design: Randomized, Double blind, Placebo-controlled trial. Setting: Paediatric unit of a Teaching hospital. Methods: 80 children between 2 months- 5 years with diagnosis of pneumonia and severe pneumonia (as per the WHO definition) admitted over a period of one year were included. Children with features of rickets, severe malnutrition, history of asthma, any underlying medical disorders and vitamin D supplementation over the last 12 months were excluded. Children were randomized to two groups, Intervention group received 300,000 IU of Vitamin D (1ml) and the control group received $1 \mathrm{ml}$ of Sterile water as a placebo intra muscularly along with antibiotics and supportive care. Children were monitored for the resolution of symptoms. The two groups were comparable for baseline demographic, socioeconomic, clinical and laboratory parameters. Results: There was no significant difference in time to resolution of symptoms (fever, tachypnea and chest retractions) in Intervention group (3.63 \pm 1.27 days) \& placebo group (3.6 \pm 0.78 days), $\mathrm{p}=0.933)$. Conclusion: Supplementation of single high dose $(300,000 \mathrm{IU})$ of vitamin $\mathrm{D}$ given intramuscularly have no beneficial effect on the resolution of pneumonia and severe pneumonia in the children of 2 months to 5 years of age.
\end{abstract}

Keywords: Chest indrawing, Fever, Pneumonia, Rickets, Vitamin D supplementation

\section{Introduction}

Pneumonia affects 156 million and more than 2 million annual deaths in under 5-year children every year and it is the leading cause of mortality in this age group worldwide [1]. Almost all of these occur in the developing world. In India 43 million cases and 0.4 million deaths are due to pneumonia. The median incidence of pneumonia in India is estimated to be 0.37 episodes per child per year [2].

Studies have suggested an association between vitamin D deficiency and pneumonia. A study on Ethiopian children shows 13 times higher incidences of rickets among children with pneumonia than among controls [3]. Study on Nepalese children presenting with lower respiratory infection showed that low vitamin D status had significantly increased risk for treatment failure and longer illness duration [4].Vitamin D levels might

Manuscript received: $24^{\text {th }}$ February 2018

Reviewed: $4^{\text {th }}$ March 2018

Author Corrected: $10^{\text {th }}$ March 2018

Accepted for Publication: $16^{\text {th }}$ March 2018 influence ALRI (acute lower respiratory tract) disease severity, as vitamin D deficiency was found to be significantly associated with children admitted to the paediatric intensive care unit with severe acute lower respiratory infection [5]. Research has shown that Vitamin D plays an important role in modulating the innate immune responses against infections. 1,25dihydroxy vitamin D $(1,25 \mathrm{D})$, the active form of vitamin $\mathrm{D}$ acts via the Vitamin $\mathrm{D}$ receptor which induces antimicrobial peptides (cathelicidin).

These are vanguards of innate immune responses against bacterial, fungal and viral pathogens [6]. Studies have shown subclinical vitamin D deficiency in infants and children was associated with severe acute lower respiratory infection in studies from India and Turkey $[7,8]$. Even though India is located in tropical region with abundant sunlight, vitamin D deficiency is common. Several studies in south Asian population have reported high prevalence of hypovitaminos is D, 
despite living in areas with abundant UVB radiation. Sun-avoidant behaviour leaves many dependent on diets for intake of vitamin $\mathrm{D}$, which are inadequate in fulfilling vitamin D requirements [9]. The average adult diet typically provides $<10-20 \%$ of an individual's vitamin D stores which in a child's diet is likely to provide even lesser [10]. Breast feeding may not provide enough vitamin $\mathrm{D}$ for infants especially if mothers are also vitamin $\mathrm{D}$ deficient $[7,8,11]$. The complementary or replacement foods in the diets of Indian infants and children are not fortified with vitamin D [7]. Hence supplementation with vitamin D remains the most appropriate option available.

Inspite of the evidence there are very few studies done on vitamin D supplementation in children with pneumonia $[12,13]$. Hence this study was conducted to test whether vitamin D supplementation in children presenting with pneumonia and severe pneumonia reduce the duration of illness.

\section{Materials and Methods}

This randomized double blind, place bocontrolled trial was conducted on children between the age group of 2 months-5years presenting with pneumonia and severe pneumonia in the paediatric department of a teaching hospital over a period of one year.

Pneumonia was diagnosed (according to WHO definition) in children presenting with cough, cold and fast breathing (respiratory rate $\geq 50$ per minute in $2 \mathrm{~m}$ $12 \mathrm{~m} ; \geq 40$ per minute in $12 \mathrm{~m}-5 \mathrm{y}$ ). If the children presented with chest in drawing along with the above symptoms then it was diagnosed as severe pneumonia [14]. Children with clinical features of rickets (craniotabes, frontal bossing, rachitic rosary, Harrison groove, enlargement of wrist and ankle), severe malnutrition (weight for height/ length $<-3 \mathrm{SD}$, with or without oedema, with or without MUAC $<11.5 \mathrm{~cm}$ ), history suggestive of asthma, any underlying disorders (cough >2weeks, tuberculosis, congenital heart diseases, retroviral disease, epilepsy, nephritic syndrome, bleeding disorder) and if received any vitamin D supplementation over the last 12 months were excluded.

Written informed consent was taken from either of the parents. Approval of Institutional ethical committee was taken. Subjects were randomized to two groups according to a computer generated random number table. Group allocation was concealed in a brown opaque envelope. Intervention group received $1 \mathrm{ml}$ (300,000 IU Vitamin D3, Abbott India Limited) of
Vitamin D intramuscularly and the control group received similar looking $1 \mathrm{ml}$ of Sterile water as a placebo over the lateral aspect of thigh. The attached labels of the ampoules of Vitamin D3 and Sterile water were removed by the pharmacist who was not aware of the groups, so that they appeared similar and were given a unique identity number which was sealed. The identity was opened after the intervention, data collection, follow-up and tabulation were completed. The ampoules were stored in a dry and cool environment according to the manufacturer's recommenddations. The investigators and the caretakers of the subjects were unaware of the study groups.

Both the groups received antibiotics in the form of IV Penicillin G $(2,00,000 \mathrm{U} / \mathrm{kg} /$ day in four divided doses $)$ along with supportive care in the form of oxygen, intravenous fluids and antipyretics (Paracetamol at $15 \mathrm{mg} / \mathrm{kg} /$ dose).

Detail history, demographic data, socioeconomic status (by using Kuppuswamy socioeconomic status scale modified for 2007 [15]), immunisation status, history of breast feeding \& complementary feeding practice, exposure to smoking, type of fuel used for cooking (LPG/ non-LPG) at home and housing conditions were recorded in a structured proforma. Detailed clinical examination along with anthropometry as per the standard techniques was also recorded. Respiratory rate was recorded for one full minute for two times with the child unclothed and when it was awake and not crying.

Axillary temperature was checked using digital thermometer using standard technique. Venous blood was drawn for haemoglobin, blood counts, Serum calcium and alkaline phosphatase. Blood culture was collected separately under all aseptic precautions. Chest radiograph was done in all the children which was reported by a qualified radiologist who was not aware of the study groups.

All the children wereclinically monitored and details of the pulse rate, respiratory rate, temperature, chest in drawing and feeding was recorded every 8 hourly. If the clinical signs (fever, tachypnea and chest in drawing) persisted for more than 48 hours or if they worsened then it was considered as deterioration or failure to treat. In such cases antibiotics were stepped up to cefotaxime $(150 \mathrm{mg} / \mathrm{kg} /$ day individed 8 hourly dose intravenously). Improvement of tachypnea, fever and chest in drawing persisting for $\geq 48$ hours was considered as recovery, after which child was discharged. The duration of resolution was recorded 
from the time of study enrolment to that of recovery. All the children fulfilling the study criteria were included in the study over the period of one year of the study. Collected data was presented in percentage and proportions. Chi-square test was used to see the association and $t$ test or nonparametric test was used to see the difference between two variables. $p$ value of $<0.05$ was considered as significant

\section{Results}

During the study period 93 children were enrolled out of which 80 children were included, with 40 children in each groups. Out of the 13 children excluded, 11 parents refused consent and 2 detected to have pulmonary tuberculosis (Figure). Hence results were analysed for 80 children with 40 in each group.

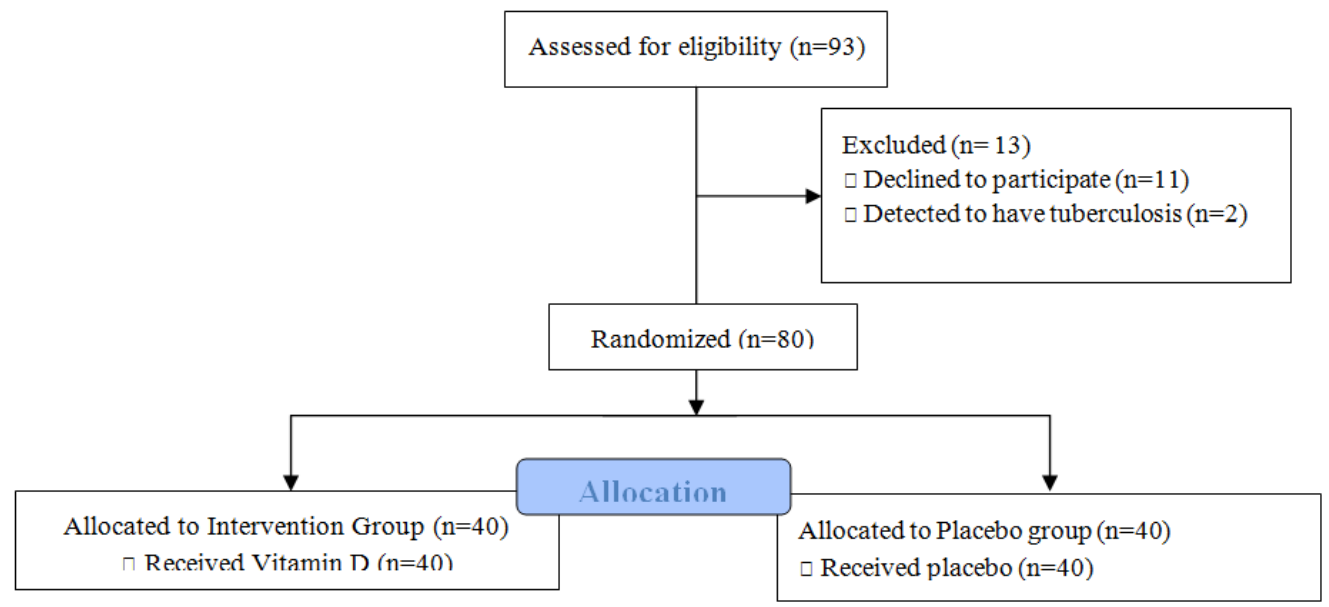

Figure: Flow Diagram

Table-I: Baseline characteristics of the groups*

\begin{tabular}{|c|c|c|}
\hline Parameter & $\begin{array}{c}\text { Intervention group } \\
\mathbf{n}(\%) \\
\end{array}$ & $\begin{array}{c}\text { Placebo group } \\
\mathbf{n}(\%)\end{array}$ \\
\hline \multicolumn{3}{|l|}{ Age } \\
\hline $2-12 \mathrm{~m}$ & $19(47.5)$ & $22(55)$ \\
\hline $12 \mathrm{~m}-5 \mathrm{y}$ & $21(52.5)$ & $18(45)$ \\
\hline Boys & $22(55)$ & $26(65)$ \\
\hline \multicolumn{3}{|l|}{ Parental education } \\
\hline Preterm birth & $7(17.5)$ & $5(12.5)$ \\
\hline Low birth weight $(<2.5 \mathrm{~kg})$ & $4(10)$ & $3(7.5)$ \\
\hline \multicolumn{3}{|l|}{ Immunization status } \\
\hline Complete & $32(80)$ & $34(85)$ \\
\hline Partial & $8(20)$ & $6(15)$ \\
\hline Previous episode of pneumonia & $4(10)$ & $3(7.5)$ \\
\hline Exclusive breast feeding & $29(72.5)$ & $32(80)$ \\
\hline Exposure to passive smoking & $5(12.5)$ & $7(17.5)$ \\
\hline \multicolumn{3}{|l|}{ Type of fuel used } \\
\hline Non-LPG & $22(55)$ & $22(55)$ \\
\hline Overcrowding ${ }^{\#}$ & $20(50)$ & $18(45)$ \\
\hline \multicolumn{3}{|l|}{ Socioeconomic status } \\
\hline Middle (Class III) & $9(27.5)$ & $11(27.5)$ \\
\hline Lower (Class IV, V) & $31(77.5)$ & $29(72.5)$ \\
\hline
\end{tabular}

*p value $>0.05,{ }^{*}$ overcrowding: $>2$ persons per room, $>3$ persons in 2 rooms, $>5$ persons in 3rooms [15] 
Both the groups were similar with respect to age, sex, low birth weight \& preterm at birth, education of the parents, exposure to smoking, type of fuel used, over crowding and socio-economic status (Table I). The number of children with previous history of pneumonia, nutritional status (weight for height) and presence of anaemia (haemoglobin $<11 \mathrm{~g} / \mathrm{dL}$ ) were equally distributed between the two groups (Table II). 24 (60\%) children out of 40 in intervention group and 26 $(65 \%)$ out of 40 in placebo group presented with pneumonia and the remaining children presented with severe pneumonia $(\mathrm{p}>0.05)$. Hence severity of pneumonia was also equally distributed between the two groups. Chest radiograph showed the features of consolidation in $15(37.5 \%)$ and $11(27.5 \%)$ in intervention and placebo respectively ( $>00.05)$. Blood culture was positivity was very low in both the groups, $[1(2.5 \%)$ and $2(5 \%)$ in intervention and placebo groups respectively $(\mathrm{p}>0.05)]$. Both the groups were comparable with respect to radiological and microbiological parameters.

Table-II: Pneumonia related characteristics

\begin{tabular}{|c|c|c|}
\hline Parameter & Intervention group n(\%) & Placebo group n(\%) \\
\hline \multicolumn{3}{|l|}{ Clinical presentation* } \\
\hline Cough and fever & $40(100)$ & $40(100)$ \\
\hline Tachypnea & $40(100)$ & $40(100)$ \\
\hline Chest indrawing & $16(40)$ & $14(35)$ \\
\hline \multicolumn{3}{|l|}{ Severity of pneumonia* } \\
\hline Pneumonia & $24(60)$ & $26(65)$ \\
\hline Severe pneumonia & $16(40)$ & $14(35)$ \\
\hline \multicolumn{3}{|l|}{ Weight for length/height* } \\
\hline Median & $19(47.5)$ & $13(32.5)$ \\
\hline$<-1 \mathrm{SD}$ & $13(32.5)$ & $21(52.5)$ \\
\hline$<-2 \mathrm{SD}$ & $8(20)$ & $6(15)$ \\
\hline Anemia $(\mathrm{Hb}<11 \mathrm{gm} / \mathrm{dL})^{*}$ & $26(65)$ & $33(82.5)$ \\
\hline $\begin{array}{l}\text { Chest radiograph showing } \\
\text { consolidation* }\end{array}$ & $15(37.5)$ & $11(27.5)$ \\
\hline Failure to recover on Penicillin $\mathrm{G}^{*}$ & $3(7.5)$ & $4(10)$ \\
\hline Blood culture positivity* & $1(2.5)$ & $2(5)$ \\
\hline $\begin{array}{l}\text { Time for resolution of symptoms } \\
\text { (days) mean }(\mathrm{SD})^{+}\end{array}$ & $3.6(0.78)$ & $3.625(1.27)$ \\
\hline
\end{tabular}

*p value $>0.05,{ }^{+}$Mann Whitney $\mathrm{U}$ test $\mathrm{p}$ value $=0.933$

Most of the children in both the groups responded to Penicillin G [36(90\%) in placebo group, 37(92.5\%) in Intervention group, $\mathrm{p}>0.05]$. Antibiotics were stepped up to cefotaxime in 3(7.5\%) children of intervention group and 4(10\%) children of control group. Time required for resolution of symptoms (fever, tachypnea and chest retractions) was almost same (3.63 \pm 1.27 days in Intervention group / 3.6 \pm 0.78 days in placebo group, $\mathrm{p}=0.933)$ and was not significant. All the children responded to the treatment and none of them developed complications of pneumonia or adverse effects of vitamin D toxicity.

\section{Discussion}

This double-blind placebo control randomized trial shows that supplementation with high dose of vitamin D3 along with antibiotics in children of age between $2 \mathrm{~m}-5 \mathrm{y}$ presenting with pneumonia and severe pneumonia does not have significant beneficial effect on the duration of recovery.

The major limitation of our study was the small sample size, as we included children presenting with pneumonia and severe pneumonia over the study period of 12 months. We could not do serum levels of vitamin $\mathrm{D}$ in our subjects before or after supplementation due to financial constraints.

The factors associated with pneumonia (birth weight, gestation, immunisation status, breast feeding, exposure to passive smoking, type of fuel used at home, anaemia, socioeconomic status, housing conditions and parental 
education) were equally distributed between the two groups. These were the modifiable risk factors associated with children aged between 1month-5years presenting with pneumonia in an Indian study [16]. We excluded children with severe malnutrition as they would be supplemented with micronutrients as a part of management. Children in our study had no clinical signs of vitamin D deficiency and hence many not receive any vitamin $\mathrm{D}$ supplementation.

However subclinical vitamin D deficiency can be a significant risk factor for severe acute lower respiratory infection as shown by V Wayse in Indian children [7] Studies have shown that susceptibility to infection occurs before many of the overt manifestations of nutritional rickets might appear [9].

There were no gross side effects detected after giving such a high dose $(300,000 \mathrm{IU})$ of vitamin D3 by intramuscular route. Study on children in Istambul (aged 6-30months) treated with the same dose $(300,000$ IU) of vitamin D for rickets was found to be safe and effective [17]. We chose to give vitamin $\mathrm{D}$ as a single high dose intramuscularly instead of oral daily or intermittent dosage due to the concerns of compliance. Also reliability of intermittent dosing was poor because of wide variability in the serum vitamin $\mathrm{D}$ concentration achieved. Doses administered intramuscularly had long lasting serum vitamin D levels for the entire year [13, $18]$.

Studies show that it takes nearly 2 months for the peak concentration of vitamin $\mathrm{D}$ to be achieved after receiving single large dose [18]. This might also be the reason why Vitamin D supplementation in our study did not reduce the duration of the current episode of pneumonia. A Cochrane review did not find benefit of vitamin D supplementation on the incidence of pneumonia in children under-five years irrespective of whether it was confirmed by hospital tests [19].

This was also evident in previous studies. Choudhary $\mathrm{N}$ found no beneficial effect of short-term supplementation with oral vitamin D (1000-2000 IU per day for 5 days) in children with severe pneumonia in under5 age group [12].

Manaseki-Holland $\mathrm{S}$ also showed that after a single high dose $(100,000)$ of vitamin D supplementation found no significant effect on the days to recovery in children aged 1-36month diagnosed with pneumonia. However, in the vitamin D supplemented children there was significant reduction in the recurrence of repeat episodes of pneumonia over a follow-up period of 90 days [13]. The possible cause might be blood levels of vitamin D might still be sub-optimal immediately after the administration of the dose for the beneficial effect to occur which might become evident over a period of time.

To conclude the result of our study shows that supplementation of single high dose $(3,00,000$ IU) of vitamin $\mathrm{D}$ given intramuscularly have no beneficial effect on the resolution of pneumonia and severe pneumonia in the children of 2 months-5years age. However long-term follow-up of these children was needed for the benefit if any to be evident. Further studies are needed to determine any beneficial effect of vitamin $\mathrm{D}$ in different settings using different dosages with a large sample size and follow-up.

\section{What this study adds: \\ Supplementation of single high dose vitamin \\ $D$ has no beneficial effect on the resolution of pneumonia and severe pneumonia in the children of 2 months to 5years of age.}

Funding: Nil, Conflict of interest: None initiated, Perission from IRB: Yes

Contributors: AD, SP \& J: conception and design of the study and interpretation of data. J: collected and analysed the data. SP: drafting of manuscript, critical revision of the manuscript for important intellectual content. The final version of the manuscript was approved by all authors.

Acknowledgement: Dr S D Kalsad, Director BIMS Belagavi for permission to conduct this study. We also thank Mrs Sunanda Halki for her assistance in statistical analysis.

\section{References}

1. Bryce J, Boschi-Pinto C, Shibuya K, Black RE; WHO Child Health Epidemiology Reference Group. WHO estimates of the causes of death in children. Lancet. 2005 Mar 26-Apr 1; 365(9465):1147-52.

2. Rudan I, Boschi-Pinto C, Biloglav Z, Mulholland K, Campbell H. Epidemiology and etiology of childhood pneumonia. Bull World Health Organ. 2008;86:408-16.

3. Muhe L, Lulseged S, Mason K, Simoes E. Casecontrol study of the role of nutritional rickets in the risk of developing pneumonia in Ethiopian children. Lancet. 1997;349:1801-4. 
4. Haugen J, Basnet S, Hardang I, Sharma A, Mathisen M, Shrestha P et al. Vitamin D status is associated with treatment failure and duration of illness in Nepalese children with severe pneumonia. Pediatr Res. 2017;82: 986-93.

5. Mc Nally J, Leis K, Matheson L, Karuanayake C. Vitamin D deficiency in young children with severe acute lower respiratory infection. Pediatr Pulmonol. 2009; 44:981-8.

6. White JH. Vitamin D signaling, infectious diseases, and regulation of innate immunity. Infect Immun. 2008 Sep; 76(9): 3837-43. doi: 10.1128/ IAI.00353-08. Epub 2008 May 27.

7. Wayse V, Yousafzai A, Mogale K, Filteau S. Association of Subclinical vitamin D deficiency with severe acute lower respiratory infection in Indian children under 5y. Eur J Clin Nutr.2004;58:563-7.

8. Karatekin G, Kaya A, Salihoğlu O, Balci H, Nuhoğlu A. Association of subclinicalvitamin D deficiency in newborns with acute lower respiratory infection and their mothers. Eur J Clin Nutr. 2009 Apr;63(4):473-7. Epub 2007 Nov 21.

9. Walker VP, Modlin RL. The vitamin D connection to pediatric infections and immune function. Pediatr Res. 2009 May; 65(5 Pt 2):106R-113R. doi: 10.1203/PDR. 0b013e31819dba91.

10. Sichert-Hellert W, Wenz G, Kersting M. Vitamin intakes from supplements and fortified food in German children \& adolescents: results from the DONALD study. J Nutr.2006;136:1329-33.

11. Bhalala U, Desai M, Parekh P, Mokal R, Chheda B. Subclinicalhypovitaminosis D among exclusively breastfed younginfants. Indian Pediatr. 2007 Dec; 44 (12): 897-901.

12. Choudhary N, Gupta P. Vitamin Dsupplementation for severepneumonia--a randomized controlled trial. Indian Pediatr.2012Jun;49(6):449-54.Epub 2011Aug 15

13. Manaseki-Holland S, Qader G, Masher M, Bruce J, Mughal Z, Chandramohan D et al. Effects of Vitamin D supplementation to children diagnosed with pneumonia in Kabul: a randomized controlled trial. Trop Med Int Health. 2010;15:1148-55.

14. WHO (1995). The management of acute respiratory infections in children, Practical guidelines for outpatient care. World Health Organization.Geneva.

15. Park K. Park's textbook of Preventive \& Social Medicine, Ed.22. Jabalpur: M/S BANARSIDAS BHANOT; 2013.

16. Savitha MR, Nandeeshwara SB, Pradeep Kumar MJ, ul-Haque F, Raju CK. Modifiablerisk factors for acute lowerrespiratory tract infections. Indian J Pediatr. 2007 May;74(5):477-82.

17. Kutluk G, Chetinkaya F \&Basak M. Comparisons of oral calcium, high dose vitamin $\mathrm{D}$ and a combination of these in the treatment of nutritional rickets in children. Journal of Tropical Pediatrics.2002;48:351-3.

18. Vieth R. Vitamin D supplementation, 25-hydroxy vitamin D concentrations, and safety. Am J ClinNutr. 1999 May; 69(5):842-56.

19. Yakoob Y, Salam A, Khan R, Bhutta A. Vitamin D supplementation for preventing infections in children under five years of age. Cochrane Database of Systematic Reviews. 2016;11. Art. No.: CD008824.

\section{How to cite this article?}

Jingi J.K, Patil S S, Desai A.S. Randomized controlled trial of the impact on the outcome of pneumonia in children receiving Vitamin D supplementation.Int J Pediatr Res. 2018;5(3):116-121. doi:10.17511/ijpr.2018.i03.03. 